\title{
The Success of Top Professional Athletes Is Not Only Success in Sports
}

\author{
Raul Matsushita1,2, Leandro Nascimento3 ${ }^{3}$, Sergio Da Silva ${ }^{3,4,5^{*}}$ \\ ${ }^{1}$ Department of Statistics, University of Brasilia, Brasilia, Brazil \\ ${ }^{2}$ Graduate Program in Business Administration, University of Brasilia, Brasilia, Brazil \\ ${ }^{3}$ Graduate Program in Economics, Federal University of Santa Catarina, Florianopolis, Brazil \\ ${ }^{4}$ Department of Economics, Federal University of Santa Catarina, Florianopolis, Brazil \\ ${ }^{5}$ Graduate Program in Economics, Federal University of Espirito Santo, Vitoria, Brazil \\ Email: * professorsergiodasilva@gmail.com
}

How to cite this paper: Matsushita, R., Nascimento, L. and Da Silva, S. (2021) The Success of Top Professional Athletes Is Not Only Success in Sports. Open Access Library Journal, 8: e7753.

https://doi.org/10.4236/oalib.1107753

Received: July 13, 2021

Accepted: July 31, 2021

Published: August 3, 2021

Copyright $\odot 2021$ by author(s) and Open Access Library Inc.

This work is licensed under the Creative Commons Attribution International License (CC BY 4.0).

http://creativecommons.org/licenses/by/4.0/

\begin{abstract}
Professional athletes are a scalable occupation that potentially allows them to make money without an equivalent increase in labor and time because they become celebrity influencers. Earnings above medians of scalable occupations show considerable variation because the right tail of their distributions decays as a power law. This fact implies that professional athletes' labor markets are of the winner-take-all type. We take data from Forbes magazine of the world's top 100 highest-paid athletes from 2012 to 2020 and calculate Pareto exponents by ordinary least squares and maximum likelihood. We find we cannot dismiss their distribution of earnings following a power law. This result means we cannot explain the mega-earnings of the highest-paid athletes by merit in sports alone.
\end{abstract}

\section{Subject Areas}

Behavioral Economics

\section{Keywords}

Power Law, Sports Economics, Earnings Distribution, Highest-Paid Athletes

\section{Introduction}

Some complain that college professors are underworked and overpaid, but few care about the earnings of professional footballers. However, thinking that the highest-paid soccer players live up to their effort on the pitch may be misleading. For example, Neymar was ranked fourth in the 2020 Forbes list of the world's 
100 highest-paid athletes despite taking part in only ten matches in 2019 . So we have reason to suspect his earnings do not depend only on effort on the pitch. His earnings come from a "celebrity influencer" rather than a "professional athlete." We can say the same for other top athletes. For this reason, we consider a Forbes list of top athletes from different labor markets because their earnings come from occupations that have something in common-they are "scalable" [1].

Occupations where one is paid by the hour are not scalable, whereas scalable occupations allow one to make money without an equivalent increase in labor and time. Non-scalable occupations present low earnings variance, which is high for scalable ones [1]. For example, physicians all have a comparable good life, but not book authors. In this market, J.K. Rowling earned $\$ 92$ million over 2018-19, James Patterson made \$70 million, and Michelle Obama earned \$36 million; the great majority of other authors earned almost nothing. According to Forbes magazine, Neymar's net worth comes not only from his club salary. Various endorsements (61 percent of his pay) make him earn more money off the pitch than on it. He also has investments and is a marketing heavyweight in a country where he is an idol to 200 million.

Professional athletes are a scalable occupation where earnings above medians show significant differences because the right tail of their distributions decays as a "power law" [1]. A quantity follows a power law when the probability of obtaining a particular value varies inversely as a power of that value. So a power law is a relation between two quantities where a relative change to one produces a relative proportional change to the other, regardless of the initial values. Power laws appear widely in physics, biology, and economics. For example, Vilfredo Pareto first found a power law when studying the distribution of wealth, where the number of people $y$ with wealth $\geq x$ is distributed as $y=x^{-\alpha}$, with the "Pareto exponent" $\alpha \approx 1.5$. Subsequently, power laws have been discovered, and Pareto exponents have been calculated for phenomena ranging from forest fires and earthquakes to mass extinctions of species and stock markets [2] [3].

A tournament effect is suggested to explain that someone who is slightly more talented than the second-place finisher wins it all. Book lovers prefer to read J.K. Rowling for $\$ 10.99$ to some unknown author for \$1.99 [4]. Executive pay varies in direct proportion to the growth of market capitalization of a firm. However, because a power law governs this growth, minimal dispersion in CEO talent can lead to significant pay differences. CEO compensation grew sixfold between 1980 and 2003, following the power law in the market capitalization growth of their firms [5]. Differences in talent and effort explain that some earn more than others, but labor markets translate such differences into much more significant earnings differences. As a result, earnings distributions follow a power law.

Moreover, right-skewed earnings distributions can be generated when there is no difference in talent at all, in the presence of network externalities created by being a "fan" [6], or by luck alone [7].

A winner-take-all market can also result from blind luck due to the "Matthew 
effect." Someone writes an academic paper quoting 50 authors of equal merit. Another researcher cites three of those 50. Because many cite references without reading the original work, a third researcher reading the second paper selects the three references for her citations. And so on. Those three authors will have a cumulative advantage through more and more citations, and thus their academic success ends up partly as a lottery. This circumstance refers to the Matthew effect: "the rich get richer, and the poor get poorer" [8].

Thus, the winner-take-all characteristic of professional athletes' labor markets can be explained deterministically or stochastically. In both cases, the earnings distribution follows a power law. The existing literature weights the role of talent and luck in success and points to two formulas: 1 ) success = talent + luck, and 2) great success $=$ a little bit more talent + a lot of luck. (See a discussion in Chapter 17 of ref. [9].) However, disentangling talent from luck in winner-take-all markets is hard work. Despite this "fair reward problem" [10], one thing is sure: The winner-take-all characteristic of labor markets-as revealed by the fingerprints of a power law-means skill alone cannot explain the high pay of top athletes [6].

To assess whether the earnings distribution of professional athletes follows a power law, we take data from Forbes magazine of the world's top 100 highest-paid athletes from 2012 to 2020 and calculate Pareto exponents using two alternative methods: ordinary least squares (OLS) and maximum likelihood (ML). We find we cannot dismiss a power law.

\section{Data and Methods}

We take the data from The World's Highest-Paid Athletes available at https://www.forbes.com/athletes/list/. We consider data from 2012 to 2020 because we wished to consider the top 100 athletes, and previous lists consider only the top 50. Kurt Badenhausen from Forbes magazine kindly sent us the data for 2016 because the link was broken at the time of our study. Our dataset is available at https://doi.org/10.6084/m9.figshare.14057948.

We employ the two most popular methods to find the Pareto exponent $\alpha$. The first estimates the power law by OLS [11]:

$$
\log \left(\operatorname{rank}_{i}-\frac{1}{2}\right)=a-\hat{\alpha} \log \left(\frac{x_{i}}{x_{m}}\right)
$$

where the shift of $\frac{1}{2}$ is a continuity correction, $\operatorname{rank}_{i}$ starts from $1, x_{m}$ is the lowest bound on earnings $x_{1}, \cdots, x_{n}$ for a sample of size $n$, and the ratio $x_{i} / x_{m}$ is the rescaled earnings for each year. And the second is an ML estimate of the Pareto exponent [3]. For the continuous case,

$$
\hat{\alpha}=n\left(\sum_{i=1}^{n} \log \frac{x_{i}}{x_{m}}\right)^{-1}
$$

where $x_{i} \geq x_{m}>0$. The Pareto exponent $\alpha$ (or shape parameter or tail index) 
describes the heaviness of the right tail, with smaller values pointing to a heavier tail.

\section{Results}

Table 1 presents the OLS estimates. We can retrieve a power law for every year from the results, for example, $\operatorname{rank}_{i} \approx e^{4.65}\left(x_{i} / x_{m}\right)^{-2.48}$ for 2020. Log-log plots of power laws give rise to straight lines, like those in Figure 1 for each year of the sample. The vertical axis represents $\log ($ rank $-1 / 2)$, and the horizontal axis measures log (earnings/lowest bound on earnings). The high $\mathrm{R}^{2}$ values in Table 1 suggest that we cannot dismiss the power-law model.

Table 1. OLS estimates (Equation (1)).

\begin{tabular}{cccccc}
\hline & $\alpha$ & S.E. & $a$ & S.E. & $\mathrm{R}^{2}$ \\
\hline 2012 & 2.88 & 0.0337 & 4.71 & 0.0172 & 0.987 \\
2013 & 2.92 & 0.0391 & 4.79 & 0.0205 & 0.983 \\
2014 & 2.67 & 0.0374 & 4.63 & 0.0197 & 0.981 \\
2015 & 2.17 & 0.0405 & 4.44 & 0.0237 & 0.967 \\
2016 & 2.89 & 0.0461 & 4.63 & 0.0224 & 0.976 \\
2017 & 3.13 & 0.0349 & 4.60 & 0.0155 & 0.988 \\
2018 & 2.27 & 0.0293 & 4.47 & 0.0168 & 0.984 \\
2019 & 2.50 & 0.0449 & 4.56 & 0.0243 & 0.969 \\
2020 & 2.48 & 0.0438 & 4.65 & 0.0250 & 0.970 \\
Pooled data & 2.57 & 0.0176 & 4.57 & 0.0093 & 0.960 \\
\hline
\end{tabular}

Note: all $p$-values in the testing of null coefficients are less than 0.0001 .

2012
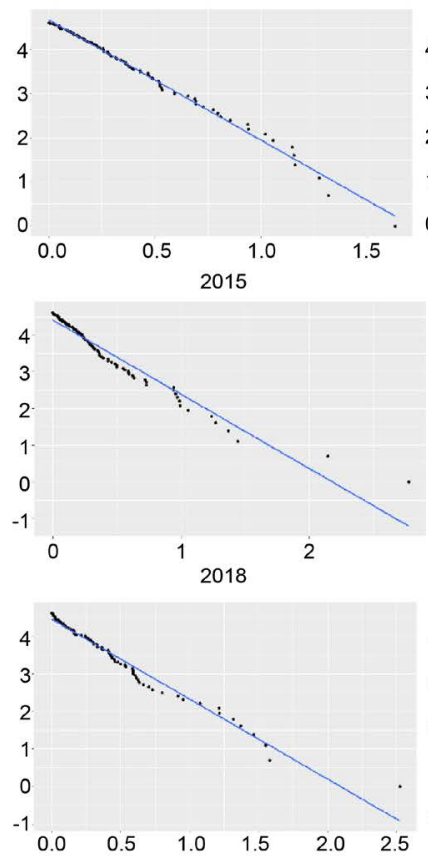

2013

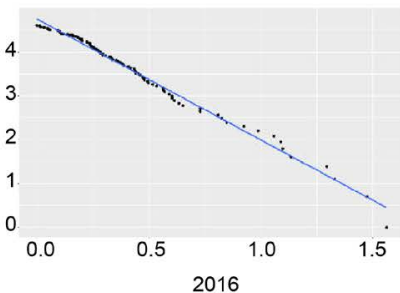

2014

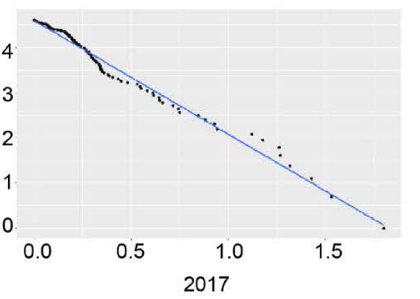

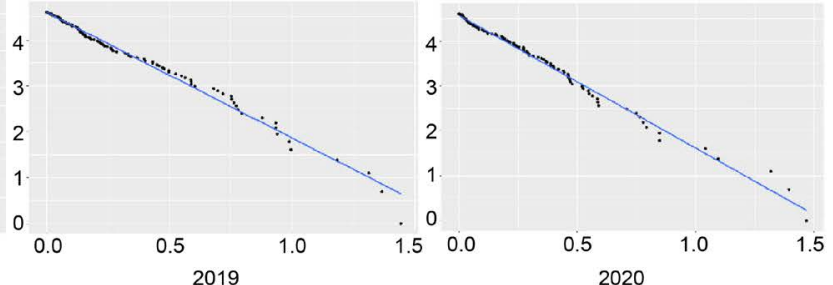

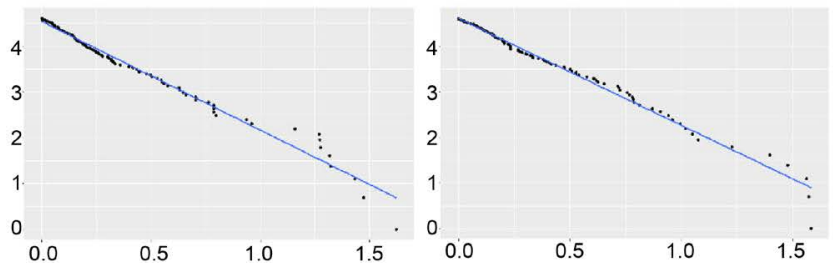

Figure 1. Power laws for the earnings distributions of the top 100 highest-paid athletes from OLS estimates. Vertical axis: $\log ($ rank - 1/2); horizontal axis: log (earnings/lowest bound on earnings). 
Figure 2 depicts an overall fit by pooling the datasets from 2012 to 2020 with $\mathrm{R}^{2}=0.960$ (the bottom row in Table 1). The straight-line refers to a general OLS Pareto index of 2.57 (S.E. $=0.0176)$ and an intercept of 4.58 (S.E. $=0.0094$ ). Therefore, we can interpret it as an average for the years 2012-2020.

Table 2 shows the ML estimates, and Figure 3 displays the dispersion between the OLS and ML estimates. The overall ML estimate of the Pareto index is 2.64 with S.E. $=0.0883$. The estimated slope between the OLS and ML dispersion is $0.994 \pm 0.035$; thus, we can conclude that both estimates are generally equivalent (Figure 3).

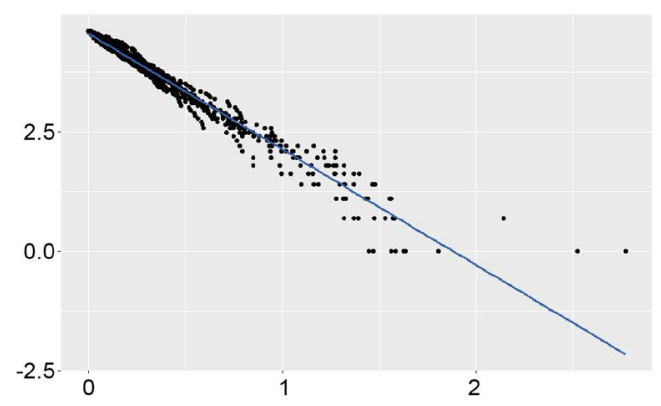

Figure 2. Power law for the pooled rescaled earnings distributions of the top 100 highest-paid athletes from OLS estimates. Vertical axis: $\log (\operatorname{rank}-1 / 2)$; horizontal axis: $\log$ (earnings/lowest bound on earnings).

Table 2. ML estimates of the Pareto exponent (equation (2)).

\begin{tabular}{ccccccccccc}
\hline & 2012 & 2013 & 2014 & 2015 & 2016 & 2017 & 2018 & 2019 & 2020 & $\begin{array}{c}\text { Pooled } \\
\text { data }\end{array}$ \\
\hline$n$ & 100 & 100 & 100 & 100 & 100 & 100 & 100 & 100 & 100 & 900 \\
$\hat{\alpha}$ & 2.62 & 2.47 & 2.62 & 2.62 & 2.83 & 3.16 & 2.63 & 2.63 & 2.39 & 2.64 \\
S.E. & 0.2624 & 0.2471 & 0.2621 & 0.262 & 0.2833 & 0.3163 & 0.2632 & 0.2628 & 0.239 & 0.0883 \\
\hline
\end{tabular}

Note: S.E. $=\hat{\alpha} / \sqrt{n}$.

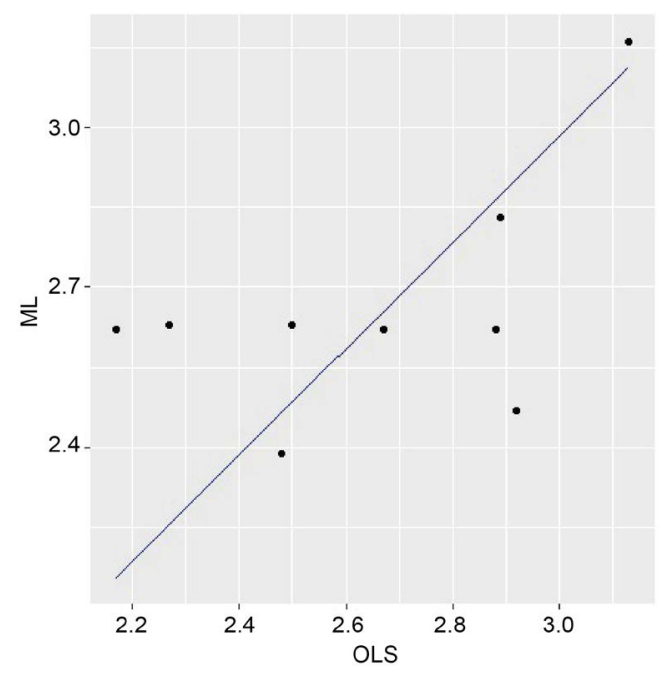

Figure 3. OLS estimate vs. ML estimate. The straight-line $\alpha_{\mathrm{ML}}=0.994 \alpha_{\mathrm{OLS}}$ with S.E. $=0.03$ suggests that $\alpha_{\mathrm{ML}}=\alpha_{\mathrm{OLS}}$, as least statistically. 


\section{Conclusion}

Top professional athletes become celebrity influencers, and this is how their occupations reveal to be scalable. We take data from Forbes magazine for the top 100 highest-paid athletes from 2012 to 2020 to study their earnings distributions. We find that the right tail of the distributions follows a power law. We calculate the Pareto exponents of the power laws using two alternative methods, ordinary least squares and maximum likelihood. We find that the estimates from both methods are generally equivalent. The overall OLS Pareto index $=2.57$ (S.E. $=$ 0.0176 ) and the overall ML Pareto index $=2.64$ (S.E. $=0.0883$ ). This power law attests to winner-take-all labor markets and thus large differences in earnings. Most important, it also means we cannot explain the mega-earnings of the highest-paid athletes by merit in sports alone. That is because much of the money comes from endorsements, not just a playing contract. So future research should pay attention to the dynamics of such endorsements, which reveals the circumstances of an athlete becoming a celebrity influencer.

\section{Financial Support}

Financial support from CNPq, Capes, FAP-DF, andDPI/UnB is acknowledged.

\section{Disclosure Statement}

The authors declare no competing interests.

\section{References}

[1] Maia, A., Matsushita, R. and Da Silva, S. (2020) Earnings Distributions of scalable vs. Non-Scalable Occupations. Physica A, 560, Article ID: 125192. https://doi.org/10.1016/j.physa.2020.125192

[2] Newman, M.E. (2005) Power Laws, Pareto Distributions and Zipf's Law. Contemporary Physics, 46, 323-351. https://doi.org/10.1080/00107510500052444

[3] Clauset, A., Shalizi, C.R. and Newman, M.E. (2009) Power-Law Distributions in Empirical Data. SIAM Review, 51, 661-703. https://doi.org/10.1137/070710111

[4] Rosen, S. (1981) The Economics of Superstars. American Economic Review, 71, 845-858.

[5] Gabaix, X. and Landier, A. (2008) Why Has CEO Pay Increased So Much? Quarterly Journal of Economics, 123, 49-100. https://doi.org/10.1162/qjec.2008.123.1.49

[6] Adler, M. (1985) Stardom and Talent. American Economic Review, 75, 208-212.

[7] MacDonald, G.M. (1988) The Economics of Rising Stars. American Economic Review, 78, 155-166.

[8] Merton, R.K. (1968) The Matthew Effect in Science. Science, 159, 56-63. https://doi.org/10.1126/science.159.3810.56

[9] Kahneman, D. (2011) Thinking, Fast and Slow. Farrar, Straus and Giroux, New York.

[10] Sornette, D., Wheatley, S. and Cauwels, P. (2019) The Fair Reward Problem: The Illusion of Success and How to Solve It. Advances in Complex Systems, 22, Article ID: 1950005. https://doi.org/10.1142/S021952591950005X 
[11] Gabaix, X. and Ibragimov, R. (2011) Rank-1/2: A Simple Way to Improve the OLS Estimation of Tail Exponents. Journal of Business \& Economic Statistics, 29, 24-39. https://doi.org/10.1198/jbes.2009.06157 